\title{
Rockburst Prediction Using Numerical Modelling- Realistic Limits for Failure Prediction Accuracy
}

\author{
T.D. Wiles Mine Modelling (Pty) Limited, Australia
}

This paper attempts to make a conclusive prediction of the time, location and magnitude of a rockburst. Through a process of back-analysis of previous rockbursts, the rockmass strength and energy release density required to induce violent failure are characterised. This information is then used to demonstrate that the conditions are right for unstable failure of a large crown pillar that subsequently failed violently. Detailed analysis of the variability in the calibration data is then used to quantify the prediction uncertainty. It is then predicted with $90 \%$ confidence that the crown-pillar will burst when its width is $33 \pm 21 \mathrm{~m}$. This represents well over half the mining life of the pillar. Even though the imminence of the impending violent failure can be predicted, the uncertainty as to the exact moment of failure is very large.

\section{INTRODUCTION}

Rockbursts pose a hazard owing to their lack of predictability. Research into understanding rockburst mechanics and implementing techniques for monitoring and prediction has been ongoing for over 50 years. Great strides have been made in control measures including ground support and ground conditioning. Seismic monitoring techniques have advanced to become very reliable, sensitive and accurate. In spite of immense effort, there has been little progress made in the prediction of rockbursting.

The objective of this paper is to demonstrate that there is a good correlation between the rockmass strength and energy release density required to induce a rockburst. A methodology is then described for determining the quantitative prediction accuracy limits. The ultimate goal is to devise a scheme to predict burst prone locations and the time in the mining sequence at which this occurs.

Although the basic mechanics of rockmass response has been well understood for some time, how this relates to rockbursting and energy release density needs additional explanation since it forms the fundamental concept used in making predictions.

\section{THE MECHANICAL BEHAVIOUR OF ROCK}

It is important to begin by discussing the yielding and unstable failure of a rockmass from a mechanistic point of view, and to show where rockbursts and numerical modelling fit into this picture. This is presented from a solid mechanics background. From this point of view it will be argued that knowledge of the loads (stress state) alone is insufficient to assess stability. The stiffness of the loading system that is driving the failure process also needs considering.

A failure criterion as shown in Fig. 1 is most often used to describe the strength of rock under load.

Unfortunately, the strength of rock and rockmass stability are not synonymous. When the stresses reach or exceed the strength, the rockmass does not necessarily become unstable. Rockmass stability depends not only on the strength/stress ratio but also on the type of failure and the loading system characteristics. It is what happens during the failure process that dictates stability. This is because it is the loading system that drives the rock through a failure process from a competent state to an unstable state -ultimately resulting in failure. This process is largely independent of the failure criterion.

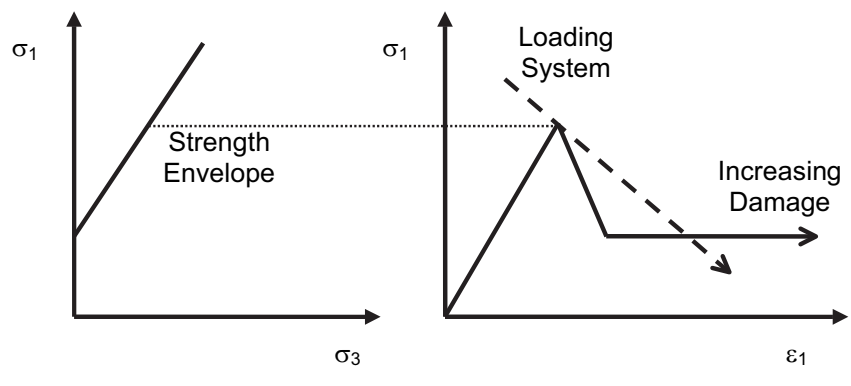

FIG. 1 Rockmass behaviour

As rock yields under excessive load, increasing amounts of damage occurs. The rock will absorb energy by cracking, loosening and eventually lose all ability to interlock. With increasing damage, at some point insufficient competency will be available to maintain stability with a given support system. This will cause failure.

In reality the relationship between elastic over-stressing and damage will be complicated by the loading system (e.g. the hangingwall/footwall) stiffness. For the same amount of over-stressing, a pillar in a soft loading system will undergo considerably more damage than one in a stiff loading system upon yielding.

A stiff loading system will increment the failure process in a controlled manner. Increasing damage will occur in sequence with mining. This condition can be readily monitored and accommodated by mine operators. By contrast, a soft loading system will tend to drive the failure process in an uncontrolled manner. Increasing damage will occur out of sequence with the mining. Large amounts of loosening and damage can occur possibly at large speeds, thereby resulting in unexpected and violent failures. This condition is not so readily monitored nor accommodated.

Knowledge of the loads alone is insufficient to assess stability. The stiffness of the loading system that is driving the failure process must also be considered. This can be achieved using elastic numerical modelling by simulating the rockmass failure. To demonstrate this, consider a pillar loaded by the hangingwall and footwall of a mine as shown in Fig. 2. 


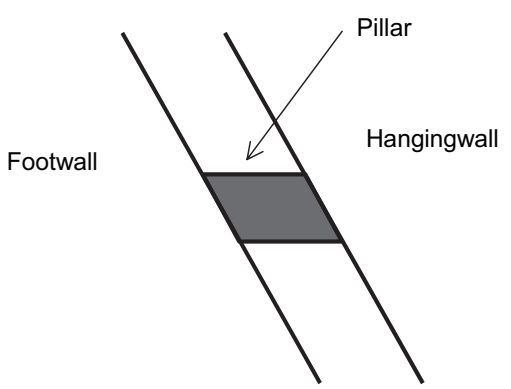

\section{FIG. 2 Mine Pillar}

The hangingwall and footwall represent the loading system. The pillar represents the sample. Using an elastic numerical model, we can simulate the pillar failure by analysing this problem in two stages:

- Stage I - intact pillar;

- Stage II - with the pillar removed.

The later stage is meant to represent the pillar in a failed state where it has been obliterated by a rockburst.

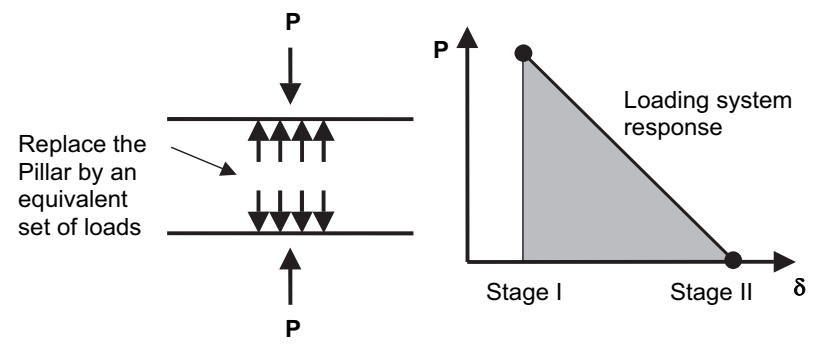

\section{FIG. 3 Simulation of pillar failure}

For a given mining geometry, one need only determine the stresses acting on the pillar (stage I), then modify these stresses (stage II) and observe how the loading system responds. The slope of the load deformation response is the loading system stiffness.

While interpretation in terms of stiffness is attractive because it is easy to understand and direct, unfortunately it is not so easy to apply (Wiles, 2002). Neither the loads nor the displacements acting on the pillar or fault are uniform. Also, the stiffness depends on the direction in which you measure the load and deformation. This makes the definition of stiffness somewhat ambiguous.

A more ubiquitous, albeit more abstract approach, is to determine the energy density (LERD). LERD is actually analogous to the loading system stiffness, the former just being the area under the load deformation curve divided by the pillar volume $V$

$$
L E R D=\iint \sigma d \delta d A / V
$$

where $\sigma$ and $\delta$ represent respectively the surface stresses and displacements, and the integrals are taken over all bounding surfaces of the pillar. Components for the normal and two shear directions must be included to arrive at the total energy released from the loading system due to 'failure' of the pillar.

For use in numerical models, this expression is normally simplified to

$$
L E R D=\sum\left(P_{I}+P_{I I}\right)\left(\delta_{I I}-\delta_{I}\right) /(2 V)
$$

where $P$ represents the normal and shear surface loads, and the sum is taken over all elements forming the boundary of the pillar.
Large loading system stiffness can be associated with low $L E R D$, while soft loading systems generally result in large $L E R D$ values. These concepts can be used interchangeably.

Note that when calculated in this way, LERD is a local rockmass characteristic whose magnitude will vary from one place to another similar to stress. The value at any location will change as stopes, accesses and drifts are mined. At some locations the LERD will increase while at others it may diminish. This means that a pillar may pass in and out of phases of being in a burst prone state as mining progresses.

\section{BACK-ANALYSIS}

To demonstrate the proposed methodology, consider the back-analyses of a series of pillar bursts. These rockbursts took place during the silling out stage at three different levels (over $2 \mathrm{Km}$ depth) of Inco's Creighton Mine during the mid-1980's (for example see Fig. 4). In all cases the failures were obvious as the pillars failed by bursting resulting in considerable displacement of material.

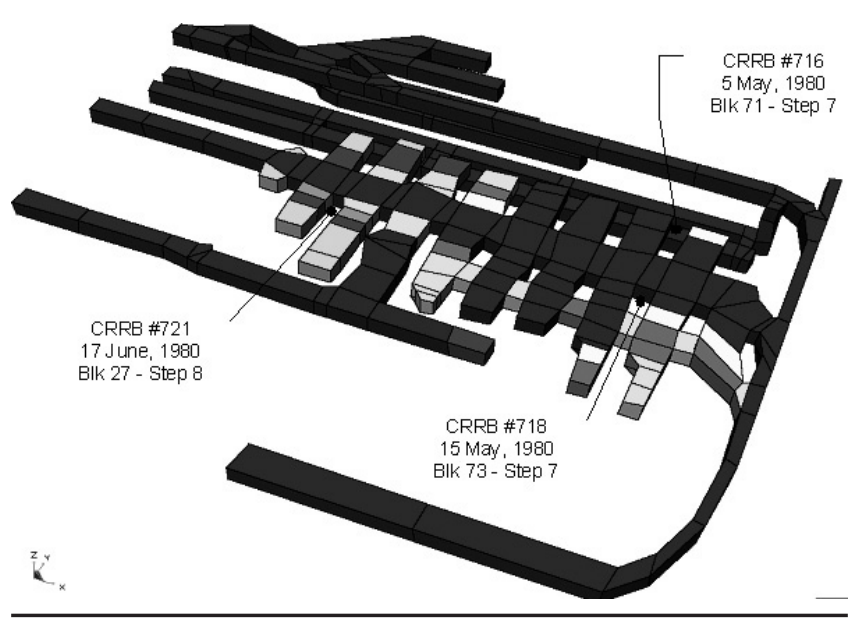

FIG. 4 Sill-pillar back-analysis

The back-analysis results are shown as the diamond shapes in Fig. 5 (Marisett, 2001 and Wiles et al., 1998).

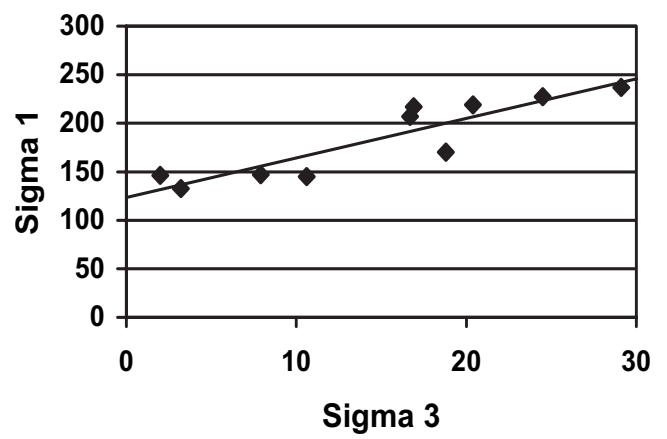

FIG. 5 Stress back-analysis of sill-pillar failures

To obtain each point, an elastic model was built and analysed using Map3D (Wiles, 2005), to determine the stress state at the centre of a pillar at the observed time of failure.

From these back-analysis results we can easily determine a best-fit strength envelope (shown as the solid inclined line) using linear regression. Doing this we find the equation for the best-fit rockmass failure criterion is given by an intercept UCS of $123.6 \mathrm{MPa}$ and a slope of 4.08 . We can assess the goodness of fit and quantify the variability (section 5). From this simple procedure it is immediately apparent if the model is working or not. 
For each of the pillar failures, the $L E R D$ can also be calculated using the procedure described above to obtain the results shown in Fig. 6.

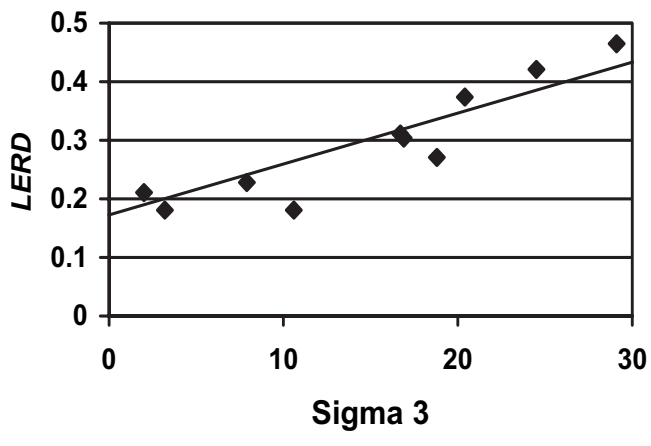

\section{FIG. 6 LERD back-analysis of sill-pillar failures}

As above, we can easily determine a best-fit line using linear regression. Doing this we find the equation for the best-fit line is given by an intercept $0.173 \mathrm{MJ} / \mathrm{m}^{3}$ and a slope of 0.0087 .

It is interesting to observe the strong dependence shown for LERD with confinement. Note that whereas for the stress back-analysis we were aiming to determine the strength envelope characteristic of the rockmass, here we have also determined the LERD envelope characteristic of the rockmass behaviour. We should anticipate that increased energy would be required for pillar failures with increasing confinement as illustrated by the area under the stress-strain curves depicted in Fig. 7.

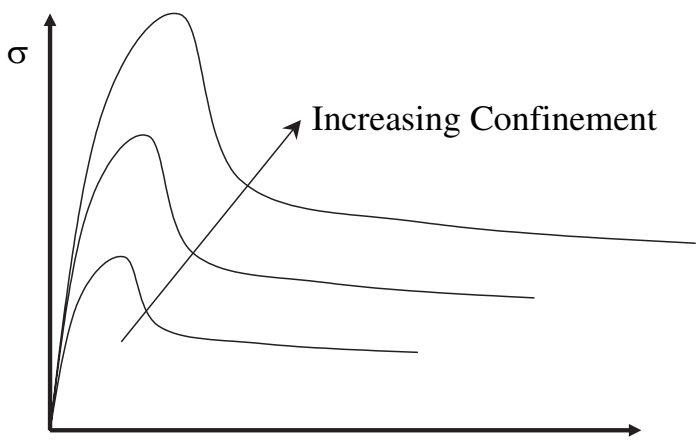

FIG. 7 LERD dependence on confinement

\section{RELIABILITY OF PREDICTIONS}

Geological materials are very non-uniform. As a consequence, the stress magnitude, strength and other characteristics will vary from point to point. Although a mean value can be defined, there will be uncertainty as to what local value would be found at any given location. Repeated measurements demonstrate that the likelihood of finding a given value can be quantified in terms of probability.

The reliability of a failure prediction can be determined using the standard methodology of probability and statistical analysis. To apply this, quantifying the mean and variability of both the rockmass strength (capacity function C) and stress predictions (demand function D) is needed, as shown in Fig. 8.

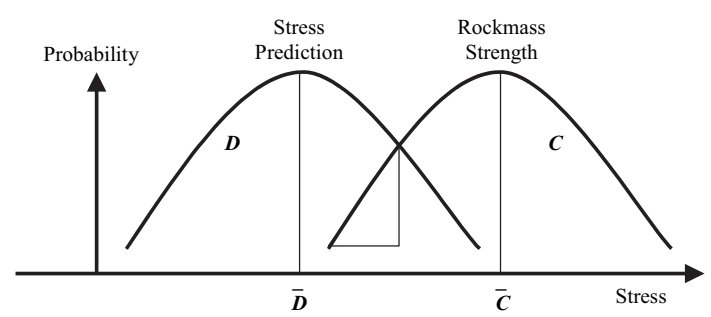

FIG. 8 Capacity versus demand

Here the vertical axis represents the likelihood that various stress levels will occur (i.e. the probability), and the width of the frequency distribution represents the variability. The factor of safety is defined as

$$
S F=\bar{C} / \bar{D}
$$

These two distributions can be subtracted to determine the probability of failure as indicated by the hatched area in Fig. 8 where the demand exceeds the capacity (Harr, 1987).

Obviously, if the variability of the two distributions changes quite different probabilities of failure with the same factor of safety can be obtained, as shown in Fig. 9.

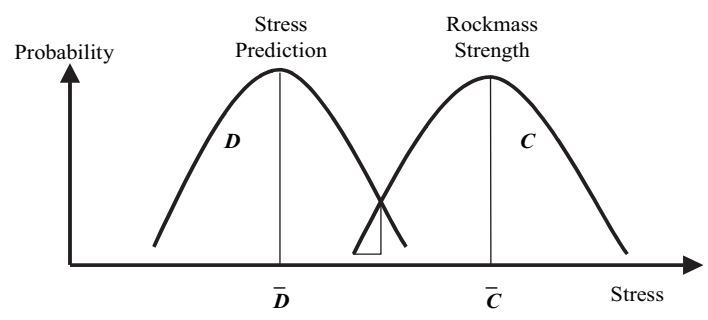

FIG. 9 Decreased variability

Although this approach appears to be quite straight forward, application to real life mining problems is not so easy. Direct determination of the probability distributions for the capacity and demand functions are all but impossible. Reliable quantification of local variability would require detailed in situ sampling and measurements of mining induced stresses and rockmass strength. This is an unrealistic objective in practical mining environments. An alternative is to use back-analysis results to quantify the variability.

\section{IN SITU PREDICTION RELIABILITY}

\subsection{Quantification of Reliability}

Quantifying the variability of the modelling predictions from back-analysis results now needs consideration. This can be readily achieved by finding a best-fit line, then calculating the mean distance from each prediction to the line.

For each back-analysis, the distance from any stress point to the best-fit line for a linear criterion is given by

$$
\Delta \sigma_{1}=\sigma_{1}-U C S-q \sigma_{3}
$$

where $\sigma_{1}$ and $\sigma_{3}$ represent respectively the major and minor principal stresses, UCS and $q$ represent respectively the rockmass unconfined compressive strength and slope of the best-fit line.

The standard deviation $s$ can be written

$$
s=\sqrt{\sum \Delta \sigma_{1}^{2} /(n-2)}
$$

where $n$ represents the number of back-analysis points, and the summation is taken for all $n$ data points. Note that $(n-2)$ represents the degrees of freedom used as a divisor to ensure 
an unbiased estimate. The best-fit line can be obtained by minimizing $s$ with respect to $U C S$ and $q$ (i.e. linear regression) as shown in Table 2.

$$
\begin{aligned}
& q=\frac{\sum\left(\sigma_{1} \sigma_{3}\right) / n-\bar{\sigma}_{1} \bar{\sigma}_{3}}{\sum\left(\sigma_{3} \sigma_{3}\right) / n-\bar{\sigma}_{3}^{2}} \\
& U C S=\bar{\sigma}_{1}-q \bar{\sigma}_{3}
\end{aligned}
$$

where $\bar{\sigma}_{1}$ and $\bar{\sigma}_{3}$ represent mean values. UCS and $q$ can be related to the cohesion Coh and friction angle $\varphi$ as follows

$$
\begin{gathered}
U C S=2 \text { Coh } \tan (45+\varphi / 2) \\
q=\tan ^{2}(45+\varphi / 2)
\end{gathered}
$$

TABLE 2 Sill-pillar back-analysis

\begin{tabular}{ccc}
\hline $\boldsymbol{\sigma}_{1}$ & $\boldsymbol{\sigma}_{3}$ & $\Delta \boldsymbol{\sigma}_{1}$ \\
\hline 216.9 & 16.9 & +24.42 \\
170.0 & 18.8 & -30.22 \\
218.9 & 20.4 & +12.16 \\
236.7 & 29.1 & -5.49 \\
227.3 & 24.5 & +3.85 \\
206.9 & 16.7 & +15.24 \\
145.1 & 10.6 & -21.71 \\
132.6 & 3.2 & -4.05 \\
146.2 & 2.0 & +14.44 \\
147.1 & 7.9 & -8.70 \\
\hline $\bar{\sigma}_{1}=184.77$ & & $S=18.39$ \\
$\sigma_{3}=15.01$ & & UCS $=123.61$ \\
$\Sigma\left(\sigma_{1} \sigma_{3}\right)=30656.09$ & & $q=4.075$ \\
$\Sigma\left(\sigma_{3} \sigma_{3}{ }^{2}=2970.17\right.$ & & Coh $=30.61$ \\
$\Sigma \Delta \sigma_{1}^{2}=2706.60$ & & $\varphi=37.3^{\circ}$ \\
& &
\end{tabular}

For the back-analysis results shown in Fig. 5 and Table 2, a standard deviation $s$ of $18.39 \mathrm{MPa}$ can be calculated. It is usually more meaningful to express this as a coefficient of variation by dividing by a representative stress magnitude. Here, the mean value of $\sigma_{1}(185 \mathrm{MPa})$ will be used giving

$$
C_{p}=s / \bar{\sigma}_{1}= \pm 9.95 \%
$$

$C_{p}$ is a parameter that represents the confidence we have in our predictive capability.

By back-analysing observation in this way, the accuracy of the modelling system has been actually tested. Here, the uncertainty associated with the knowledge of the pre-mining stress state, rockmass strength and applicability of the chosen numerical modelling procedure has been characterized. Back-analysis can be viewed as a procedure for quantifying the reliability of the entire predictive system rather than any of its individual components.

\subsection{Probability of Failure}

If the assumption is that $\sigma_{1}$ is normally distributed, the probability of failure $P_{f}$ can be readily calculated by integrating the shaded area shown in Fig. 8 or 9

$$
P_{f}=N\left(\Delta \sigma_{1} / s\right)
$$

where $\mathrm{N}$ is a function that represents the area under the standardized normal curve (Table 3).
TABLE 3 S given $P_{f}$ (Lipson and Sheth, 1973)

\begin{tabular}{ll}
\hline $\boldsymbol{P}_{f}(\%)$ & $\boldsymbol{S}$ \\
\hline 0.1 & $-3.1 \mathrm{~s}$ \\
1 & $-2.33 \mathrm{~s}$ \\
2.5 & $-1.96 \mathrm{~s}$ \\
5 & $-1.65 \mathrm{~s}$ \\
10 & $-1.28 \mathrm{~s}$ \\
50 & 0 \\
90 & $+1.28 \mathrm{~s}$ \\
95 & $+1.65 \mathrm{~s}$ \\
97.5 & $+1.96 \mathrm{~s}$ \\
99 & $+2.33 \mathrm{~s}$ \\
99.9 & $+3.1 \mathrm{~s}$ \\
\hline
\end{tabular}

Alternatively, given a desired $P_{f}$ it can be determined the corresponding stress level from the inverse normal distribution as

$$
\Delta \sigma_{1}=s N^{-1}\left(P_{f}\right)
$$

This is presented graphically in Fig. 10 where confidence intervals corresponding to Eq. 10 are plotted.

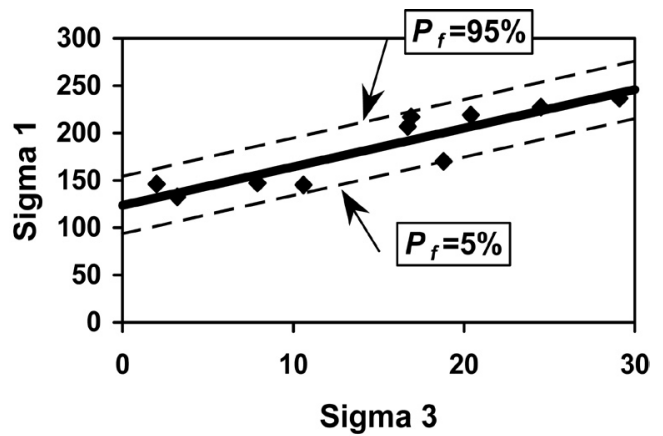

\section{FIG. 10 Confidence intervals}

For small data sets it must be realized that the calculated values for the best-fit strength envelope and standard deviation are only uncertain estimates. The accuracy of these can be refined by considering more back-analysis results. There are techniques to incorporate this extra uncertainty as a function of sample size $n$, but these details will not be considered here.

In view of this, it is not recommended that too many significant digits of accuracy be used. This is because it is not likely to be able to characterize the required parameters (bestfit line and variability) nor the applicability of the normal distribution to the required degree of accuracy. The fine details in Table 3 are only presented to illustrate how quickly the probability of failure changes best-fit line is moved away from. For example at 3 s from the mean probability of failure an error of about one in a thousand times would occur.

In the development of the methodology above, the discussion has been limited to the application of normal distributions. This simplicity has lead to many intuitive insights. If extending this to non-normal probability distribution was required, adopting Rosenbleuth's (1981) point estimate method or Monte Carlo methods would be useful. This has already been demonstrated in much detail by Hoek (1998). 


\section{PRACTICAL APPLICATIONS OF VARIABILITY CONCEPTS}

\subsection{Crown-Pillar Failure}

Now that field scale strength and LERD envelopes have been calibrated, it is time to determine the limits to the accuracy of failure prediction for a crown-pillar failure.

Several years after the sill pillar failures that were backanalysed above, the mechanized cut and fill mining had progressed to create a narrowing crown-pillar that eventually failed violently (Fig. 11).

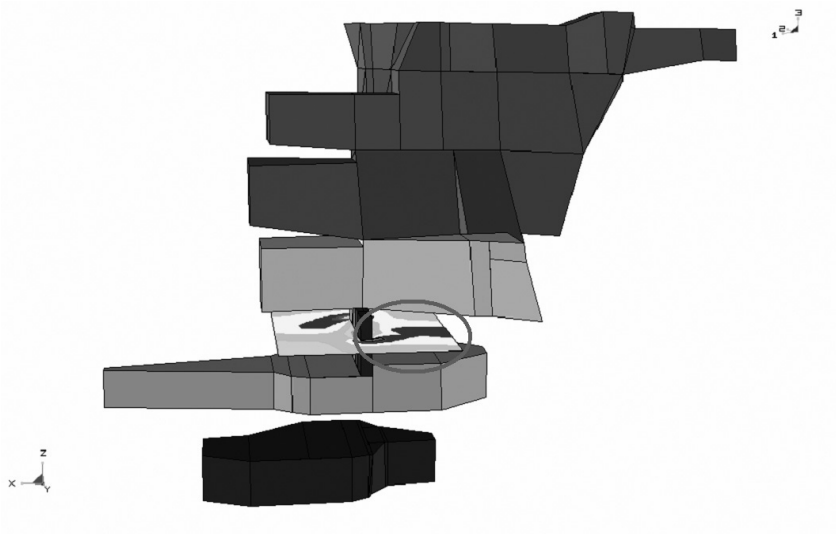

FIG. 11 Crown-pillar failure

Firstly, an examination of when to expect failure, and the anticipated nature of the failure is required. Fig. 12 shows the stress state predicted from elastic modelling for various crown-pillar widths (labelled in metres). The solid diamonds correspond to $8 \mathrm{~m}$ intervals, representing two cuts each. From the figure it can be seen that the crown pillar is expected to fail when it is approximately $38 \mathrm{~m}$ wide.

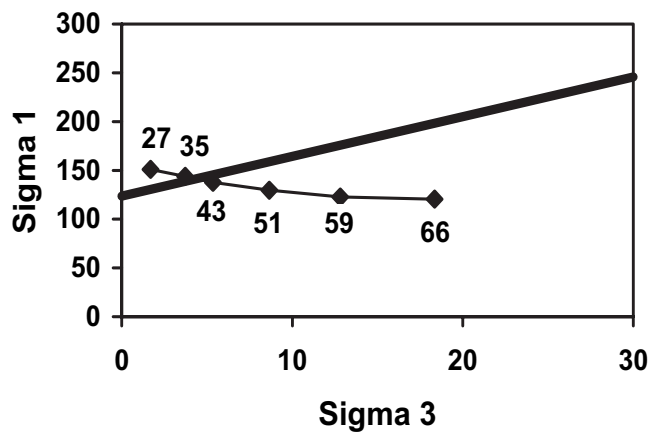

FIG. 12 Stresses in crown-pillar

Similarly, the LERD is shown in Fig. 13.

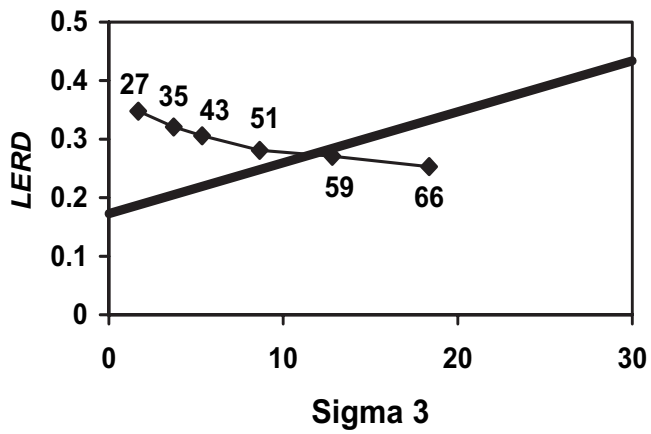

FIG. 13 LERD in crown-pillar
Interpretation of these later results needs careful consideration. In the calculation of $L E R D$, a question that requires asking is: if this pillar were to fail, how much energy would be released by $t$ he host rockmass? The results in Fig. 13 illustrate that for pillar widths of approximately $59 \mathrm{~m}$ or less, the host rockmass is releasing energy at a sufficient rate to induce a rockburst. Of course this energy would only be released if the pillar were to fail. Fig. 12 indicates that the stress level in the pillar does not reach sufficient magnitude to induce failure until the pillar is $38 \mathrm{~m}$ wide. Hence, not only is pillar failure predicted at $38 \mathrm{~m}$ width, the prediction that there will be more than sufficient energy released to induce violent failure can also be made. If the pillar volume was multiplied by the LERD (at $35 \mathrm{~m}$ width) an expected energy release Wk in the order of 13 to $26 \mathrm{GJ}$ can be obtained depending on how much of the pillar fails. Using the relation provided by Ryder and Jager (2002)

$$
\log _{10} W_{k}=1.5 M_{L}-1.2
$$

it can be calculated that this represents an expected Richter magnitude on the order of 3.5 to 3.7 .

This interpretation agrees well with the actual failure of 4300 crown that can be described (pers. com. O'Donnell and Langille, 1998) as a series of violent events. Despite the fact that the failure process took a year, it was not a slow quiet process. This included several periods of intense seismic activity concentrated in the footwall area. At least 8 rockbursts were reported varying in magnitude from 2.0 to 3.6. Water inflow (i.e. seepage through the back) was observed from the level above. Rock displaced from the back to a height of $6 \mathrm{~m}$ over the central slot and $1 \mathrm{~m}$ to $2 \mathrm{~m}$ in several of the footwall panels. The footwall contact was a continuous source of ground control problems. The hangingwall drift along the top edge of the pillar became impassable.

The accuracy of this prediction seems impressive.

\subsection{Reliability of the Prediction}

Now, the probability technique discussed above needs to be applied in order to determine exactly how accurately this prediction may be made without the benefit of hindsight.

The details of the stress predictions for various pillar widths are given in Table 4. Here Eq. 9 has been used to calculate the $P_{f}$

TABLE 4 Crown-pillar details

\begin{tabular}{lllll}
\hline Width & $\sigma_{1}$ & $\sigma_{3}$ & $\Delta \sigma_{1} / \mathbf{s}$ & $\mathbf{P}_{\mathrm{f}}(\%)$ \\
\hline 66 & 120.6 & 18.35 & -4.23 & 0.001 \\
59 & 122.9 & 12.81 & -2.88 & 0.20 \\
51 & 129.8 & 8.65 & -1.58 & 5.71 \\
43 & 137.8 & 5.35 & -0.41 & 34.1 \\
$35^{*}$ & 144.0 & 3.72 & +0.28 & 61.0 \\
27 & 151.1 & 1.69 & +1.12 & 86.9 \\
\hline
\end{tabular}

* failure

This is presented graphically in Fig. 14 and 15. 


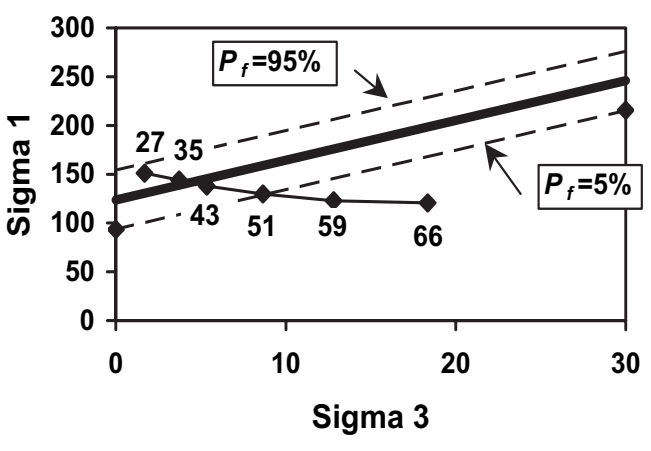

FIG. 14 Stresses in crown-pillar

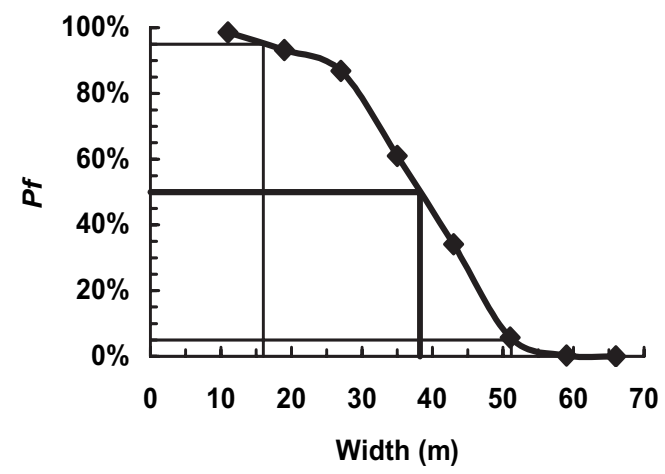

FIG. $15 P_{f}$ in crown-pillar

By interpolation in Table 4 or from Fig. 15 it can be determined that the crown-pillar is expected to fail when its width is between $16 \mathrm{~m}$ and $51 \mathrm{~m}$, or approximately $33 \pm 18 \mathrm{~m}$, with $90 \%$ confidence ( $95 \%$ minus $5 \%$ ). This can be expressed as a prediction variability of $\pm 55 \%$ (i.e. $\pm 18 / 33$ ).

\section{DISCUSSION}

The purpose of this paper is to determine if the moment of failure can be predicted? Above it was predicted with $90 \%$ confidence that the crown pillar would fail when its width is $33 \pm 18 \mathrm{~m}$. This uncertainty represents well over half the mining life of the pillar. In terms of predicting the exact moment of failure, this is clearly not a very useful prediction.

On a positive note, even though the moment of failure cannot be predicted, it is very certain that the crown-pillar is going to fail in the middle 9 cuts. In addition, the energy calculations show that this is very likely to be a violent rockburst with a Richter magnitude of 3.5 to 3.7.

Close observation of Eq. 9 and Table 4 indicates that the prediction accuracy could be refined if the magnitude of $s$ and hence $C_{p}$ was somehow reduced. There are two main contributing factors.

\subsection{Rockmass Variability}

For a given site, there is an inherent background level of uncertainty due to the variability associated with the in situ stress, strength and changing geology. The magnitude of this contribution could be reduced if we could spatially correlate our rockmass failure criterion to match these changes.

Here, incorporating additional geological details into the model in the hope for a better match with actual changing conditions across our site could be considered. This may be as simple as introducing zones with different stiffness or pre-mining stress states. However, it is unclear whether the increase in accuracy anticipated by use of a more complex model is offset by the uncertainty introduced by the additional input parameters. It is conceivable that less reliable predictions could be obtained because of this. Certainly, backanalysis would be required for confirmation.

Instead of trying to model the geological complexity, a simpler alternative is to determine a heterogenous rockmass strength distribution. Consistent success has been achieved by Nicholls (1992) by broadly defining lithological units across his mine sites. Application of the conventional method could be extremely useful in deciding how this should proceed.

Recently, attempts have been made to directly modify the rockmass response by physically loading the numerical model though incorporation of seismicity (Lachenicht et al., 2001 and Wiles et al., 2001). So far these have achieved limited success.

\subsection{Numerical Modelling Technique}

When large values of $s$ are found from back-analysis, it is possible that this arises from use of an inappropriate modelling technique. Obvious causes for this can include illposed models (2D versus 3D), geometric construction errors or numerical approximation errors. These problems can be readily dealt with and are really not the issue here.

In heavily loaded mines where significant stress transfer occurs as a result of yielding ground, homogeneous elastic models may not provide accurate predictions. Here we could consider introducing non-linear slip planes to model important structural features. Plasticity theory can be used to effect stress transfer. Block models can be used if unravelling is a dominant feature.

One must be very cautious in proceeding on this course. In addition to adding more complex simulation capability, we are also adding more assumptions and hence uncertainty. Despite our good intentions, it is entirely possible that we will end up with less reliable predictions because of this. Starfield and Cundall (1988) think this is so important that they have devoted an entire paper to addressing this issue.

It should also be noted that in order to make use of complex modelling techniques, more work is required in terms of time, calibration, verification and interpretation of results. Mine operators are generally chronically short on time for such investigations. Given a limited budget and time, more information will likely be gained by running many simple models rather than a few complex ones.

\section{CONCLUSIONS}

Reliable predictions regarding the location and magnitude of an impending rockburst have been demonstrated using a well calibrated numerical model. Although the failure is imminent, prediction of the exact time is very uncertain.

Back-analysis shows that predictions can be made with uncertainty $C_{p}$ of less than $10 \%$ in terms of stress. Using this, it was predicted with $90 \%$ confidence that the crown pillar would fail when its width is $33 \pm 18 \mathrm{~m}$, an uncertainty representing well over half the pillar width. Unfortunately, the uncertainty in terms of stress is greatly amplified in application to provide large uncertainty in terms of pillar width at the moment of failure.

Higher accuracy predictions could be obtained with lower values of $C_{p}$. The back-analyses conducted here provided a prediction uncertainty $\mathrm{Cp}$ of $10 \%$. In view of the fact that geo-materials generally exhibit coefficients of variation in the order of $20 \%$ to $30 \%$, it is somewhat surprising that such a low value was obtained. This indicates that the predictive system is matching field observations very well.

Even by incorporating improved geological detail and more complex modelling capabilities, it seems unlikely that values for $C_{p}$ significantly smaller than $10 \%$ could ever be attained. High accuracy conclusive predictions may not be 
possible in a geological environment. It seems unlikely that the necessary low values of $C_{p}$ are possible owing to the natural variability of the rockmass.

Detailed analysis of the calibration data can be used to characterize the variability and quantify the prediction uncertainty. Predictions of failure with known accuracy limits can then be made. As a result, cost and safety related decisions could be made with a known level of confidence providing real numbers that can be used to guide an engineering judgement.

The observational approach is well defined and can be easily used to quantify prediction variability with a minimum of engineering effort. When this method can be applied, it represents the best way of quantifying accuracy limits. This also quantifies the predictive capability of our entire system. Included are the rockmass variability, assumptions regarding input parameters and applicability of the chosen modelling technique.

\section{ACKNOWLEDGMENTS}

The author is grateful to Inco for permitting publication of details and analysis results from Creighton Mine.

\section{REFERENCES}

Harr, M.E. (1987) Reliability Based Design in Civil Engineering, McGraw-Hill Book Company.

Hoek, E. (1998) Reliability of Hoek-Brown Estimates of Rockmass Properties and their Impact on Design, Int. J. Rock. Mech. Min. Sci., Vol. 35, No. 1, pp. 63-68.

Lachenicht, R., Wiles, T.D. and van Aswegen, G. (2001) Integration of deterministic modelling with seismic monitoring for the assessment of rockmass response to mining: Part II Applications, 5th International Symposium on Rockbursts and Seismicity in Mines (RaSiM 5), Sandton, South Africa.

Lipson, C. and Sheth, N.J. (1973) Statistical Design and Analysis of Engineering Experiments, McGraw-Hill Book Company, New York.

Marisett, S.D. (2001) Assessing Pillar Design at Inco's Creighton Mine using the Local Energy Release Density Method, M.A.Sc. Thesis, Queen's University, Kingston, Canada.

Nicholls, D. (1992) personal communication.

O'Donnell, J.D.P. and Langille, C. (1998) personal communication.

Rosenbleuth, E. (1981) Two-point estimates in probabilities, J. Appl. Math. Modelling, Vol. 5, pp. 329-335.

Ryder, J.A. and Jager, A.J. (2002) A textbook on rock mechanics for tabular hard rock mines, The Safety in Mines Research Advisory Committee (SIMRAC), Johannesburg, South Africa.

Starfield, A.M. and Cundall, P.A. (1988) Towards a methodology for rock mechanics modelling, Int. J. of Rock Mech. Min. Sci., Vol. 25, No. 3, pp. 99-106.

Terzaghi, K. and Peck, R.B. (1967) Soil Mechanics in Engineering Practice, John Wiley \& Sons, New York.

Wiles, T.D., Marisett, S.D. and Martin, C.D. (1998) Correlation Between Local Energy Release Density and Observed Bursting Conditions at Creighton Mine, Mine Modelling Report, Sudbury, Canada.

Wiles, T.D., Lachenicht, R. and van Aswegen, G. (2001) Integration of deterministic modelling with seismic monitoring for the assessment of rockmass response to mining: Part I Theory, 5th International Symposium on Rockbursts and Seismicity in Mines (RaSiM 5), Sandton, South Africa.

Wiles, T.D. (2002) Loading system stiffness - A parameter to evaluate rockburst potential, 1st Int. Seminar on Deep and High Stress Mining, Perth, Australia.

Wiles, T.D., Villaescusa, E. and Windsor, C.R. (2004) Rock reinforcement design for overstressed rock using three dimensional numerical modelling, 5th Int. Symp. on Ground Support in Mining and Underground Construction (Ground Support 2004), Perth, Australia.

Wiles, T.D. (2005) Map3D User's Manual, Mine Modelling (Pty) Report. 